\title{
Role of Inducible Nitric Oxide Synthase in Regulation of Pulmonary Vascular Tone in the Late Gestation Ovine Fetus
}

\author{
Robyn L. Rairigh, ${ }^{\star}{ }$ Timothy D. Le Cras, ${ }^{\star}$ D. Dunbar Ivy, ${ }^{\star}$ John P. Kinsella, ${ }^{\star \ddagger}$ Gresham Richter, ${ }^{\star}$ Marilee P. Horan, ${ }^{\star}$ I-Da Fan, \\ and Steven H. Abman*\| \\ *Pediatric Heart Lung Center and ${ }^{\ddagger}$ Section of Neonatology, ${ }^{\S}$ Section of Cardiology, and ${ }^{\|}$Section of Pulmonary and Critical Care \\ Medicine, Department of Pediatrics, University of Colorado School of Medicine, Denver, Colorado 80218
}

\begin{abstract}
Nitric oxide (NO) produced by NO synthase (NOS) modulates fetal pulmonary vascular tone and contributes to the fall in pulmonary vascular resistance (PVR) at birth. Although the inducible (type II) NOS isoform is present in human and rat fetal lungs, it is uncertain whether type II NOS activity contributes to vascular NO production in the fetal lung. To determine whether type II NOS is present in the ovine fetal lung and to study the potential contribution of type II NOS on the regulation of basal PVR in the fetus, we measured the hemodynamic effects of three selective type II NOS antagonists: aminoguanidine (AG), 2-amino-5,6-dihydro-6-methyl-4H-1,3 thiazine (AMT), and $S$-ethylisothiourea (EIT). Studies were performed after at least $72 \mathrm{~h}$ of recovery from surgery in 19 chronically prepared fetal lambs $(133 \pm 3 \mathrm{~d} ; 147 \mathrm{~d}$, term). Brief intrapulmonary infusions of AG (140 mg), AMT (0.12 mg), and EIT (0.12 mg) increased basal PVR by 82,69 , and $77 \%$, respectively $(P<0.05)$. The maximum increase in PVR occurred within $20 \mathrm{~min}$, but often persisted up to $80 \mathrm{~min}$. These agents also increased mean aortic pressure but did not alter the pressure gradient between the pulmonary artery and aorta, suggesting little effect on tone of the ductus arteriosus. Acetylcholine-induced pulmonary vasodilation remained intact after treatment with selective type II NOS antagonists, but not after treatment with the nonselective NOS blocker, nitro-L-arginine. Using Northern blot analysis with poly(A) ${ }^{+}$RNA, we demonstrated the presence of two mRNA transcripts for type II NOS (4.1 and $2.6 \mathrm{~kb})$ in the fetal lung. We conclude that the type II NOS isoform is present in the ovine fetal lung, and that selective type II NOS antagonists increase PVR and systemic arterial pressure in the late-gestation fetus. We speculate that type II NOS may play a physiological role in the modulation of vascular tone in the developing fetal lung.
\end{abstract}

Address correspondence to Dr. Robyn L. Rairigh, The Children's Hospital, Neonatology, Box B070, 1056 E. 19th Avenue, Denver, CO 80218-1088. Phone: 303-861-6868; FAX: 303-764-8117; E-mail: robyn. rairigh@UCHSC.edu

Received for publication 17 July 1997 and accepted in revised form 17 October 1997.

J. Clin. Invest.

(c) The American Society for Clinical Investigation, Inc. 0021-9738/98/01/0015/07 \$2.00

Volume 101, Number 1, January 1998, 15-21

http://www.jci.org
(J. Clin. Invest. 1998. 101:15-21.) Key words: nitric oxide • pulmonary circulation - pulmonary hypertension - persistent pulmonary hypertension of the newborn • lung development

\section{Introduction}

Nitric oxide (NO) ${ }^{1}$ is produced by NO synthase (NOS) during the conversion of L-arginine to L-citrulline, and plays an important role in the regulation of vascular tone in the developing lung circulation. NO modulates basal pulmonary vascular tone in the late gestation fetus (1-3), and mediates pulmonary vasodilation to several physiologic and pharmacologic stimuli, such as acetylcholine (ACh), shear stress, and oxygen $(1,2,4$, 5). In addition, endothelial NO production contributes to a decrease in pulmonary vascular resistance (PVR) at the time of birth (1, 2, 6-9). Inhibition of NOS with L-arginine analogues increases basal PVR, selectively blocks endothelium-dependent vasodilation to many stimuli, and attenuates the fall in PVR at birth (1).

Three distinct isoforms of NOS have been identified: type I, or neuronal NOS; type II, or inducible NOS; and type III, or endothelial NOS (10). Types I and III NOS are constitutive, regulated in part by calcium and calmodulin, and changes in expression of these isoforms have been characterized during fetal lung development $(6,10-13)$. Type III NOS is predominantly present in vascular endothelial cells early in gestation in sheep, rat, and human lung, and appears to be developmentally regulated $(6,11,12)$. Type I NOS has been identified in lung neuronal, epithelial, and endothelial cells, and expression increases with advancing fetal age in the rat (12-14). Type II NOS has been identified in the endothelium, epithelium, and macrophages in human and fetal rat lung by immunostaining $(13,14)$. Type II NOS is distinct from the other isoforms in that its activity is independent of intracellular calcium and it is regulated at the transcriptional level primarily through induction by endotoxin and cytokines (10). Type II NOS has been associated predominately with states including septic shock and inflammation (15-21), but its role in normal physiology is uncertain.

1. Abbreviations used in this paper: ACh, acetylcholine; AG, aminoguanidine; AMT, 2-amino-5,6-dihydro-6-methyl-4H-1,3-thiazine; Ao, ascending aorta; AoP, aortic pressure; EIT, $S$-ethylisothiourea; LA, left atrium; L-NA, nitro-L-arginine; LPA, left pulmonary artery; MPA, main pulmonary artery; NO, nitric oxide; NOS, nitric oxide synthase; PAP, pulmonary artery pressure; PVR, pulmonary vascular resistance. 
Although past studies have emphasized the role of the type III NOS isoform as the source of vascular NO production in the perinatal lung (11-13), arginine analogues that were used to inhibit NOS activity in physiologic studies were not isoform selective $(1-4,7,8)$. Whether other NOS isoforms, including type II NOS, contribute to NO activity in the normal perinatal pulmonary circulation is unknown. A recent study demonstrated constriction of the pulmonary artery, aorta, and ductus arteriosus in the fetal rat after maternal administration of a type II NOS inhibitor (15). Although these findings suggest the possibility that type II NOS activity may contribute to vascular tone in the fetal rat lung, it is uncertain if these hemodynamic effects were due to direct blockade of type II NOS in the fetal lung, or secondary to constrictor effects on the maternal or placental circulation.

Type II NOS has been studied extensively in experimental models of circulatory shock, autoimmune disease, and chronic inflammation (18-21), but whether it plays a constitutive role or contributes to NO production in the normal fetal lung is uncertain. To test whether type II NOS contributes to basal PVR in the fetal lung, we studied the hemodynamic effects of three selective type II NOS antagonists: aminoguanidine (AG), 2-amino-5,6-dihydro-6-methyl-4H-1,3 thiazine (AMT), and $S$-ethylisothiourea (EIT) (22-29) in chronically prepared fetal lambs. We compared these responses with the effects of nitroL-arginine (L-NA), a nonselective NOS inhibitor. Finally, we performed Northern blot analysis to determine whether type II NOS is present in the fetal lung.

\section{Methods}

Surgical preparation and physiological measurements. All procedures and protocols were reviewed and approved by the Animal Care and Use Committee at the University of Colorado Health Sciences Center. 19 mixed breed (Columbia-Rambouillet, Santa Monica, CA) pregnant ewes between 125 and $128 \mathrm{~d}$ of gestation (term $=147 \mathrm{~d}$ ) were fasted $24 \mathrm{~h}$ before surgery. Ewes were sedated with intravenous pentobarbital sodium (2-4 mg) and anesthetized with $1 \%$ tetracaine hydrochloride $(3 \mathrm{mg}$ ) by lumbar puncture. Preoperative doses of intramuscular ampicillin $(500 \mathrm{mg})$ and gentamicin $(2 \mathrm{~g})$ were administered. Ewes were kept sedated with pentobarbital but breathed spontaneously throughout surgery. Under sterile conditions, the left forelimb of the fetal lamb was delivered through a uterine incision. A skin incision was made under the left forelimb after local infiltration with $1 \%$ lidocaine. Polyvinyl catheters were inserted into the axillary artery and vein and advanced into the ascending aorta (Ao) and superior vena cava, respectively. A left axillary to sternal thoracotomy exposed the heart and great arteries. Polyvinyl catheters were inserted into the left pulmonary artery (LPA), main pulmonary artery (MPA), and left atrium (LA) by direct puncture and secured in position by purse string sutures. A 6-mm ultrasonic flow transducer (Transonic Systems, Inc., Ithaca, NY) was placed around the LPA to measure blood flow to the left lung. The thoracotomy and skin incision were closed, and the fetus was gently placed in the uterus. A catheter was placed in the amniotic space, ampicillin $(500 \mathrm{mg})$ was administered into the amniotic cavity, and the hysterotomy was closed. The catheters and flow transducer cable were tunneled subcutaneously to an external pouch on the ewe. Ampicillin $(250 \mathrm{mg}$ ) was infused daily in the fetal vein and amniotic cavity during the first $3 \mathrm{~d}$ after surgery. Animals were allowed at least $72 \mathrm{~h}$ for recovery from surgery before studies were performed. Catheter patency was ensured by daily infusions of heparinized saline $(100 \mathrm{U} / \mathrm{ml})$. The Ao, MPA, LA, and amniotic cavity catheters were connected to a computer-driven pressure transducer and recorder (Biopac Systems Inc.,
Santa Barbara, CA). Pressures were referenced to the amniotic cavity pressure. The pressure transducer was calibrated with a mercury column manometer. The flow transducer cable was attached to an internally calibrated flowmeter (Transonic Systems, Inc.) for continuous measurements of LPA flow. The absolute values of flows were determined from phasic blood flow signals as previously described $(30,31)$. Pulmonary vascular resistance was calculated with the following equation: PVR, $\mathrm{mmHg} / \mathrm{ml} / \mathrm{min}=$ mean MPA pressure - mean LA pressure/LPA flow. Arterial blood gas tensions, $\mathrm{pH}$, hemoglobin, and oxygen saturation were measured from blood samples that were drawn from the Ao catheter and measured at $39.5^{\circ} \mathrm{C}$ with a blood gas analyzer and hemoximeter (model OSM-3; Radiometer, Copenhagen, Denmark).

Drug preparation. All drugs were freshly prepared on the day of study. AG (Tocris Cookson Inc., St. Louis, MO), at a dose of $140 \mathrm{mg}$, was dissolved in $2 \mathrm{ml}$ of sterile saline. AMT (Tocris Cookson Inc.) and EIT (Tocris Cookson Inc.) at a dose of $0.12 \mathrm{mg}$ each were dissolved in $2 \mathrm{ml}$ of sterile saline. L-NA (Sigma Chemical Co., St. Louis, MO) at a dose of $20 \mathrm{mg}$ was dissolved with $1 \mathrm{M} \mathrm{HCl}$, then 1 $\mathrm{ml}$ of normal saline was added. $1 \mathrm{M} \mathrm{NaOH}$ was added to titrate the pH to $7.40 .200 \mathrm{mg} / \mathrm{ml} \mathrm{ACh} \mathrm{(Sigma} \mathrm{Chemical} \mathrm{Co.)} \mathrm{was} \mathrm{dissolved} \mathrm{in}$ sterile saline and infused at a dose of $1.5 \mu \mathrm{g} / \mathrm{min}$ for $10 \mathrm{~min}$ (total vol $2 \mathrm{ml}$ ) before and after each of the study drugs AG, AMT, EIT, and L-NA.

Experimental design. The identical protocol was followed for each drug: AG (140 mg, $n=7$ animals, mean gestational age, $133 \mathrm{~d}$ ); AMT (0.12 mg, $n=6$ animals, mean gestational age, $132 \mathrm{~d})$; EIT (0.12 $\mathrm{mg}, n=5$ animals, mean gestational age, $133 \mathrm{~d}$ ); L-NA (20 mg, $n=3$ animals, mean gestational age, $133 \mathrm{~d}$ ). After $30 \mathrm{~min}$ of stable baseline hemodynamic measurements, ACh $(1.5 \mu \mathrm{g} / \mathrm{min}$ for $10 \mathrm{~min})$ was infused into the LPA using a precalibrated syringe infusion pump. Hemodynamic measurements were recorded at 10-min intervals for $30 \mathrm{~min}$. One of the study drugs was infused into the LPA over a 10-min period. Hemodynamic measurements were recorded at $10-$ min intervals for $30 \mathrm{~min}$. A second dose of ACh $(1.5 \mu \mathrm{g} / \mathrm{min}$ for 10 min) was infused into the LPA for comparison with the initial vasodilator response. Arterial blood gas tensions, $\mathrm{pH}$, and oxygen saturation were measured from the Ao catheter at baseline and 30 min after the infusion of each study drug.

Northern blot analysis. Northern blot analysis was performed as previously described $(8,32)$. Briefly, total RNA was purified from fetal sheep lung (nonsurgical; $136 \mathrm{~d}$ of gestation; four animals) and then from the lungs of a rat injected with bacterial LPS to induce type II NOS expression. The rat was injected with LPS from Salmonella typhi (Sigma Chemical Co.) and killed after $6 \mathrm{~h}$. Total RNA was purified using TRIREAGENT ${ }^{\text {TM }}$ (Molecular Research Center Inc., Cincinnati, OH) by the method of Chomczynski (33). Poly(A) ${ }^{+}$RNA was purified from the total RNA using oligo(dT) affinity chromatography. $20 \mu \mathrm{g}$ of total RNA from the LPS rat and $20 \mu \mathrm{g}$ of poly(A) ${ }^{+}$ RNA from fetal sheep lungs (two samples of pooled RNA, each sample from two animals) were analyzed using standard Northern blot and hybridization techniques with cDNA probes (34). Mouse and human type II NOS cDNA probes were labeled with ${ }^{32} \mathrm{P}$ using a random-primed DNA labeling mix (GIBCO BRL, Gaithersburg, MD). Hybridization was performed with both probes simultaneously in $6 \times$ SSC, $10 \times$ Denhardt's solution, $0.1 \%$ SDS, $5 \%$ dextran sulfate 500 (Pharmacia Fine Chemicals, Piscataway, NJ), $1 \mathrm{mM}$ EDTA, $10 \mathrm{mM}$ sodium phosphate buffer, $\mathrm{pH} 7.0,100 \mu \mathrm{g} / \mathrm{ml}$ denatured salmon sperm DNA, at $65^{\circ} \mathrm{C}$. Washing conditions were as follows: $1 \times$ SSC $0.1 \%$ SDS, twice for $15 \mathrm{~min}$ at room temperature, then $0.4 \times$ SSC $0.1 \%$ SDS, twice for $15 \mathrm{~min}$ at $50^{\circ} \mathrm{C}$, then $0.4 \times \mathrm{SSC} 0.1 \%$ SDS, twice for 15 min at $65^{\circ} \mathrm{C}$. Imaging of ${ }^{32} \mathrm{P}$ signals was performed using a PhosphorImager (Storm 860; Molecular Dynamics, Sunnyvale, CA).

Data analysis. Data are presented as mean \pm SEM. Statistical analysis was performed with the Statview 4.5 software package (Abacus Concepts Inc., Berkeley, CA). Comparisons of two discrete time points were made by an analysis of variance for repeated measures with post-hoc analysis. $P<0.05$ was considered significant. 

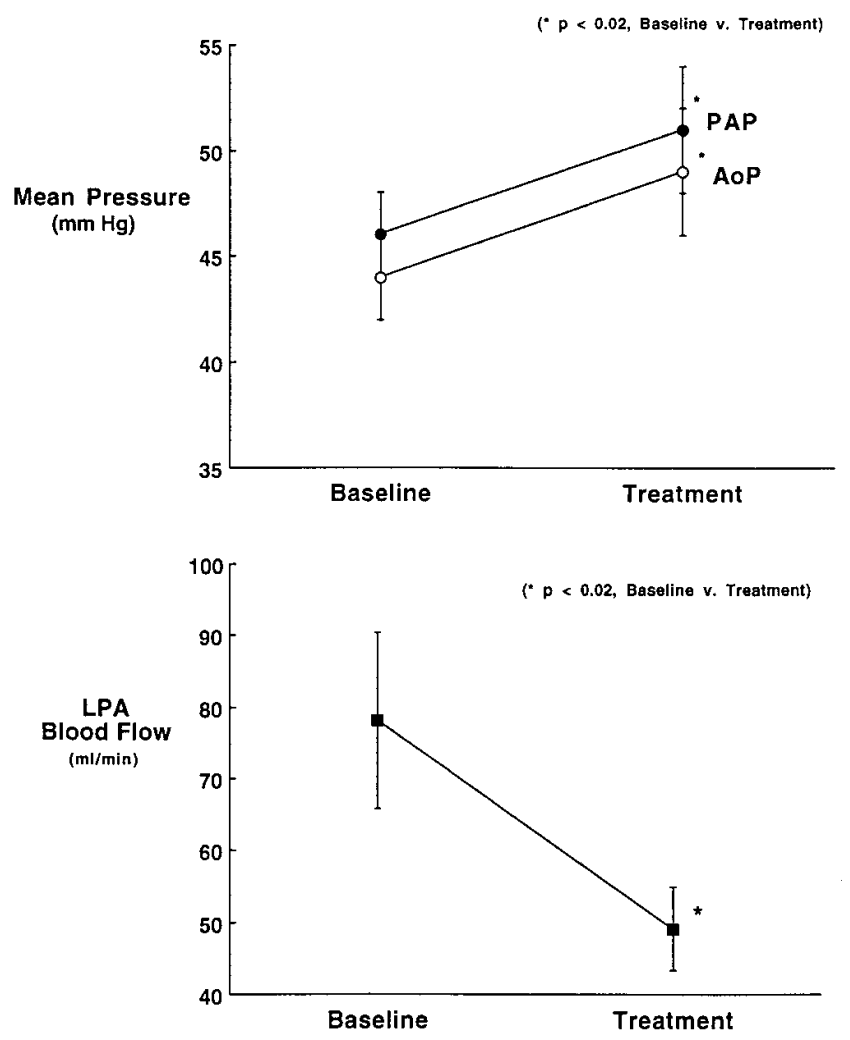

Figure 1. Hemodynamic effects of AG in the chronically prepared late gestation fetus. Brief infusions of AG $(140 \mathrm{mg})$ increased mean $\mathrm{PAP}$ and AoP, without increasing the pressure gradient between the pulmonary artery and aorta (top), and decreased LPA blood flow (bottom)

\section{Results}

Hemodynamic effects of type II NOS inhibitors in the late gestation fetal lung. AG increased mean pulmonary artery pressure (PAP) (45 \pm 2 [baseline] vs. $51 \pm 3 \mathrm{mmHg}$ [treatment]; $P<$ $0.05)$ and caused a parallel rise in aortic pressure (AoP) $(44 \pm 2$ [baseline] vs. $49 \pm 3 \mathrm{mmHg}$ [treatment]; $P<0.05$ (Fig. 1). The pressure gradient between the pulmonary artery and aorta did not change after the infusion of AG. AG decreased LPA blood flow (78 \pm 12 [baseline] vs. $49 \pm 6 \mathrm{ml} / \mathrm{min}$ [treatment]; $P<0.05$ ) (Fig. 1). Arterial blood gas tensions, $\mathrm{pH}$, oxygen saturation, and heart rate did not change after AG infusion (Table I).
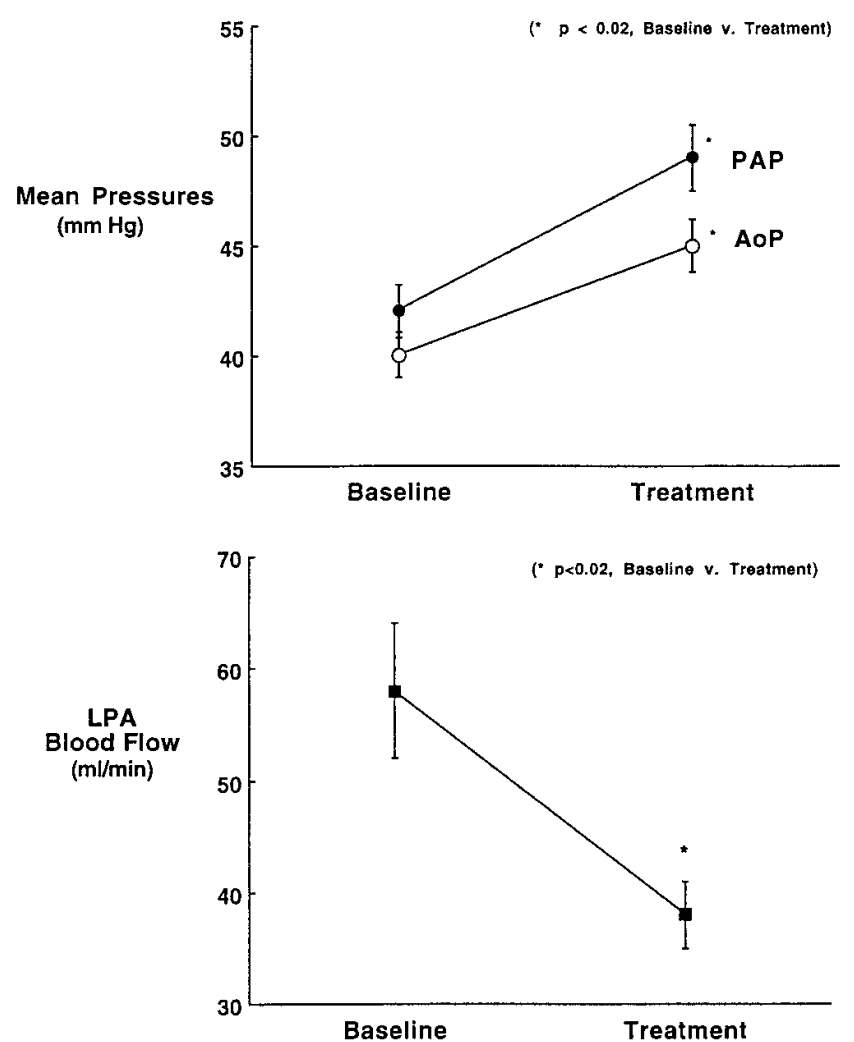

Figure 2. Hemodynamic effects of AMT in the chronically prepared late gestation fetus. Brief infusions of AMT $(0.12 \mathrm{mg})$ increased mean PAP and AoP, without increasing the pressure gradient between the pulmonary artery and aorta (top), and decreased LPA blood flow (bottom).

AMT increased mean PAP (42 \pm 1 vs. $49 \pm 1 \mathrm{mmHg} ; P<$ $0.001)$ and caused a similar rise in AoP $(40 \pm 1$ vs. $46 \pm 1 \mathrm{mmHg}$; $P<0.001$ ) (Fig. 2). The pressure gradient between the pulmonary artery and aorta did not change after the infusion of AMT. AMT also decreased LPA flow ( $58 \pm 6$ vs. $38 \pm 3 \mathrm{ml} / \mathrm{min}$; $P<0.05$ ) (Fig. 2). Arterial blood gas tensions, $\mathrm{pH}$, oxygen saturation, and heart rate did not change after AMT infusion (Table I).

EIT increased mean PAP $(43 \pm 2$ vs. $49 \pm 3 \mathrm{mmHg} ; P<$ $0.05)$ and caused a similar increase in AoP (42 \pm 2 vs. $47 \pm 2$ mmHg; $P<0.01$ ) (Fig. 3). The pressure gradient between the pulmonary artery and aorta did not change after the infusion

Table I. Effects of Selective Type II NOS Antagonist on Arterial Blood Gas Tensions, pH, Hemoglobin, and Oxygen Saturation

\begin{tabular}{|c|c|c|c|c|c|c|}
\hline & \multicolumn{2}{|c|}{$\mathrm{AG}$} & \multicolumn{2}{|c|}{ AMT } & \multicolumn{2}{|c|}{ EIT } \\
\hline & Baseline & Treatment & Baseline & Treatment & Baseline & Treatment \\
\hline $\mathrm{pH}(\mathrm{U})$ & $7.39 \pm 0.01$ & $7.37 \pm 0.01$ & $7.42 \pm 0.01$ & $7.42 \pm 0.01$ & $7.41 \pm 0.03$ & $7.41 \pm 0.03$ \\
\hline $\mathrm{P}_{\mathrm{O} 2}(\mathrm{mmHg})$ & $20 \pm 2$ & $21 \pm 2$ & $17 \pm 1$ & $17 \pm 1$ & $16 \pm 1$ & $17 \pm 1$ \\
\hline $\mathrm{P}_{\mathrm{CO} 2}(\mathrm{mmHg})$ & $42 \pm 2$ & $44 \pm 3$ & $41 \pm 1$ & $41 \pm 1$ & $44 \pm 4$ & $45 \pm 3$ \\
\hline Hemoglobin (g/dl) & $6 \pm 1$ & $6 \pm 1$ & $5 \pm 1$ & $6 \pm 1 *$ & $6 \pm 1$ & $6 \pm 1$ \\
\hline Saturations (\%) & $59 \pm 6$ & $58 \pm 5$ & $58 \pm 1$ & $60 \pm 3$ & $54 \pm 1$ & $55 \pm 1$ \\
\hline Heart rate (bpm) & $168 \pm 4$ & $159 \pm 5$ & $163 \pm 6$ & $158 \pm 3$ & $155 \pm 3$ & $160 \pm 7$ \\
\hline
\end{tabular}

Values are mean \pm SEM. $* P<0.05$, baseline vs. treatment. 

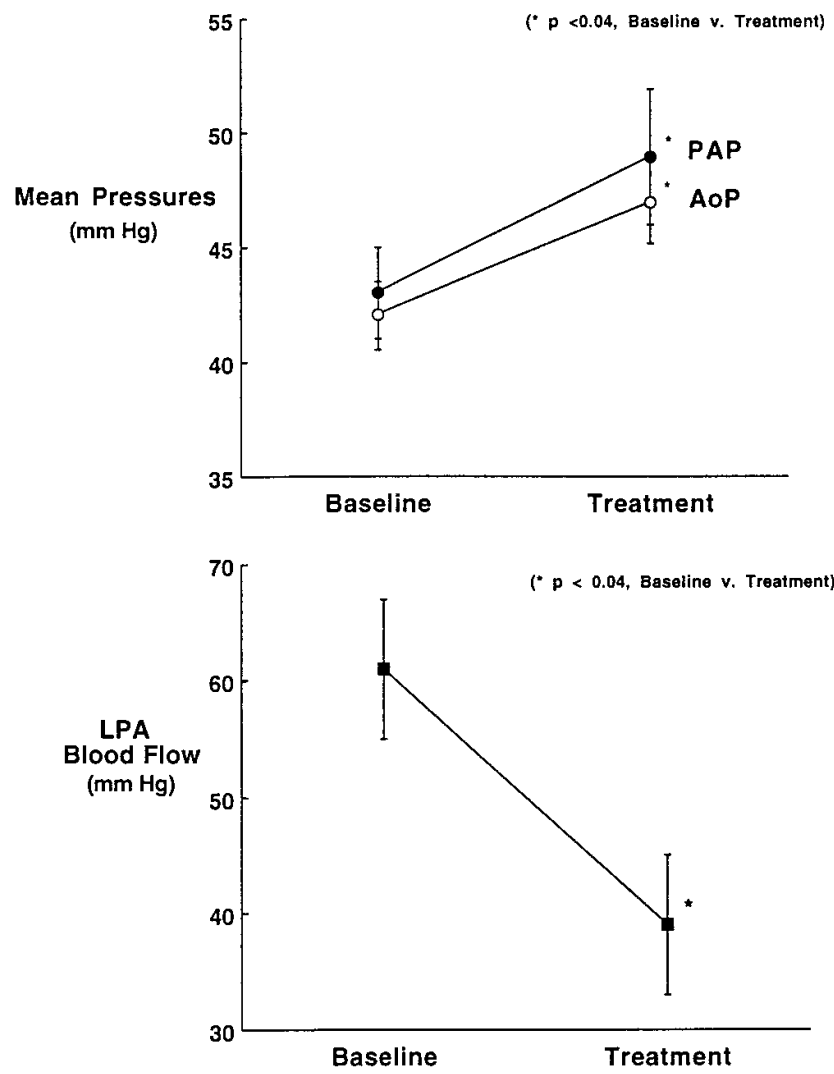

Figure 3. Hemodynamic effect of EIT in the chronically prepared late gestation fetus. Brief infusions of EIT $(0.12 \mathrm{mg})$ increased mean $\mathrm{PAP}$ and AoP, without increasing the pressure gradient between the pulmonary artery and aorta (top), and decreased LPA blood flow (bottom).

of EIT. EIT decreased LPA blood flow ( $60 \pm 6$ vs. $35 \pm 5 \mathrm{ml} /$ min; $P<0.05$ ) (Fig. 3). Arterial blood gas tensions, $\mathrm{pH}$, oxygen saturation, and heart rate did not change after EIT infusion (Table I). At the doses used in this study, AG, AMT, EIT, and L-NA increased basal PVR by $82,69,77$, and $71 \%$, respec- tively (Fig. 4). This increase in PVR persisted up to $80 \mathrm{~min}$ (Fig. 5).

Effects of NOS inhibitors on ACh-induced pulmonary vasodilation in the late gestation fetal lung. ACh decreased PVR by $40 \pm 11,43 \pm 3$, and $47 \pm 11 \%$ before the infusion of $A G$, AMT, and EIT, respectively (Fig. 6). The pulmonary vasodilator response to ACh was not decreased after treatment with the selective type II NOS antagonists. In contrast, ACh-induced pulmonary vasodilation was blocked after treatment with the nonselective NOS antagonist, L-NA (Fig. 6).

Northern blot analysis of type II NOS in fetal lung. A single type II NOS mRNA transcript of $4.1 \mathrm{~kb}$ was detected in the total RNA from the LPS rat lung (Fig. 7). In the nonsurgical fetal lamb, two mRNA transcripts for type II NOS were detected in the poly $(\mathrm{A})^{+}$RNA from the fetal lungs of 4.1 and 2.6 $\mathrm{kb}$ (Fig. 7). The 4.1-kb transcript corresponded to the type II NOS mRNA detected in the LPS rat lung (Fig. 7).

\section{Discussion}

We found that three selective type II (inducible) NOS inhibitors, AG, AMT, and EIT increased PVR and systemic arterial pressure in the chronically prepared fetal lamb. These inhibitors did not increase the pressure gradient between the pulmonary artery and aorta, suggesting a lack of significant effect on basal tone of the ductus arteriosus. The nonselective NOS antagonist, L-NA, elevated PVR to a similar degree as the type II NOS inhibitors at the doses used in this study. However, in contrast to L-NA, the type II NOS antagonists did not block ACh-induced pulmonary vasodilation, suggesting that the effects of the type II NOS inhibitors were not due to type III (endothelial) NOS blockade. These findings suggest that the inducible or type II NOS isoform contributes to basal production of NO and modulates pulmonary and systemic vascular tone in the late gestation fetus.

We were able to demonstrate that type II NOS mRNA is expressed in the near term ovine fetal lung. Two mRNA transcripts were detected by Northern blot analysis at 4.1 and 2.6 $\mathrm{kb}$. The larger transcript corresponds in size to the type II NOS mRNA induced by LPS injection of a rat. We believe that the smaller 2.6-kb type II NOS transcript is a specific sig-

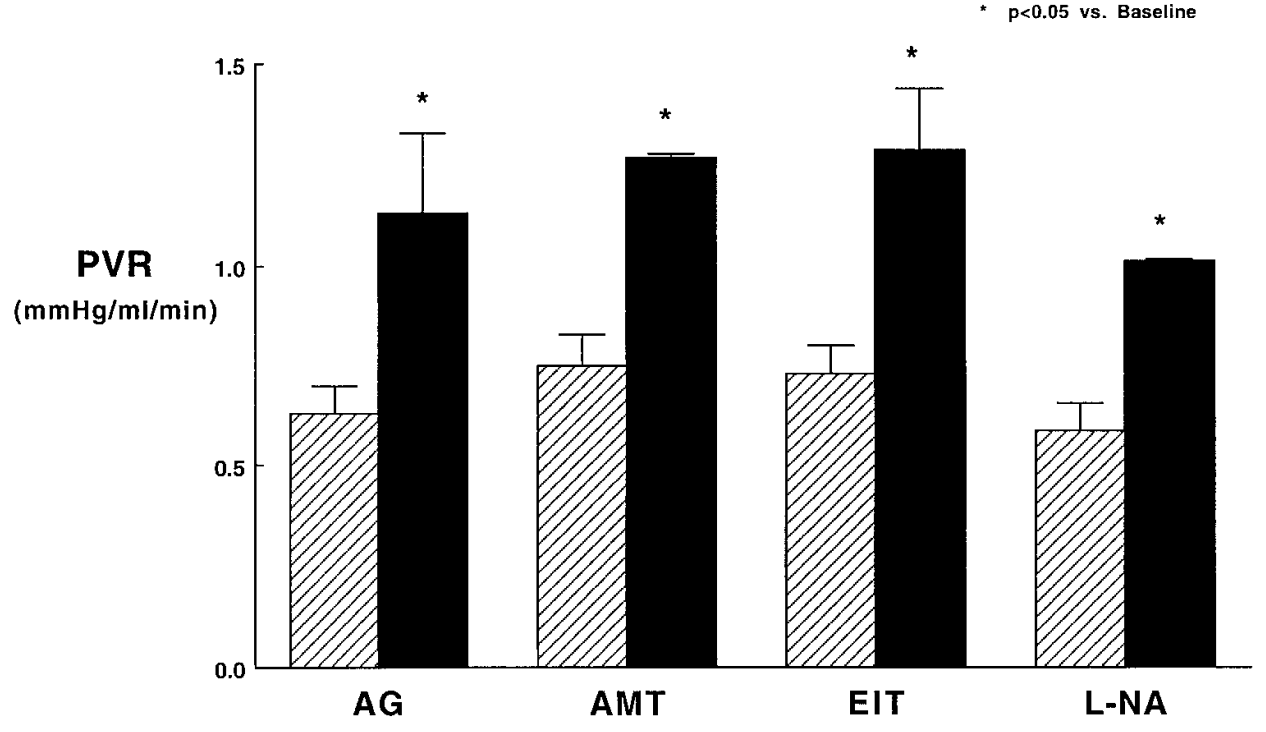

Figure 4. Effects of selective type II NOS antagonists (AG, AMT, and EIT), and the nonselective NOS antagonist L-NA, on fetal PVR. Brief infusions of each agent increased basal PVR. Hatched bars, baseline value; solid bars, peak treatment response. 


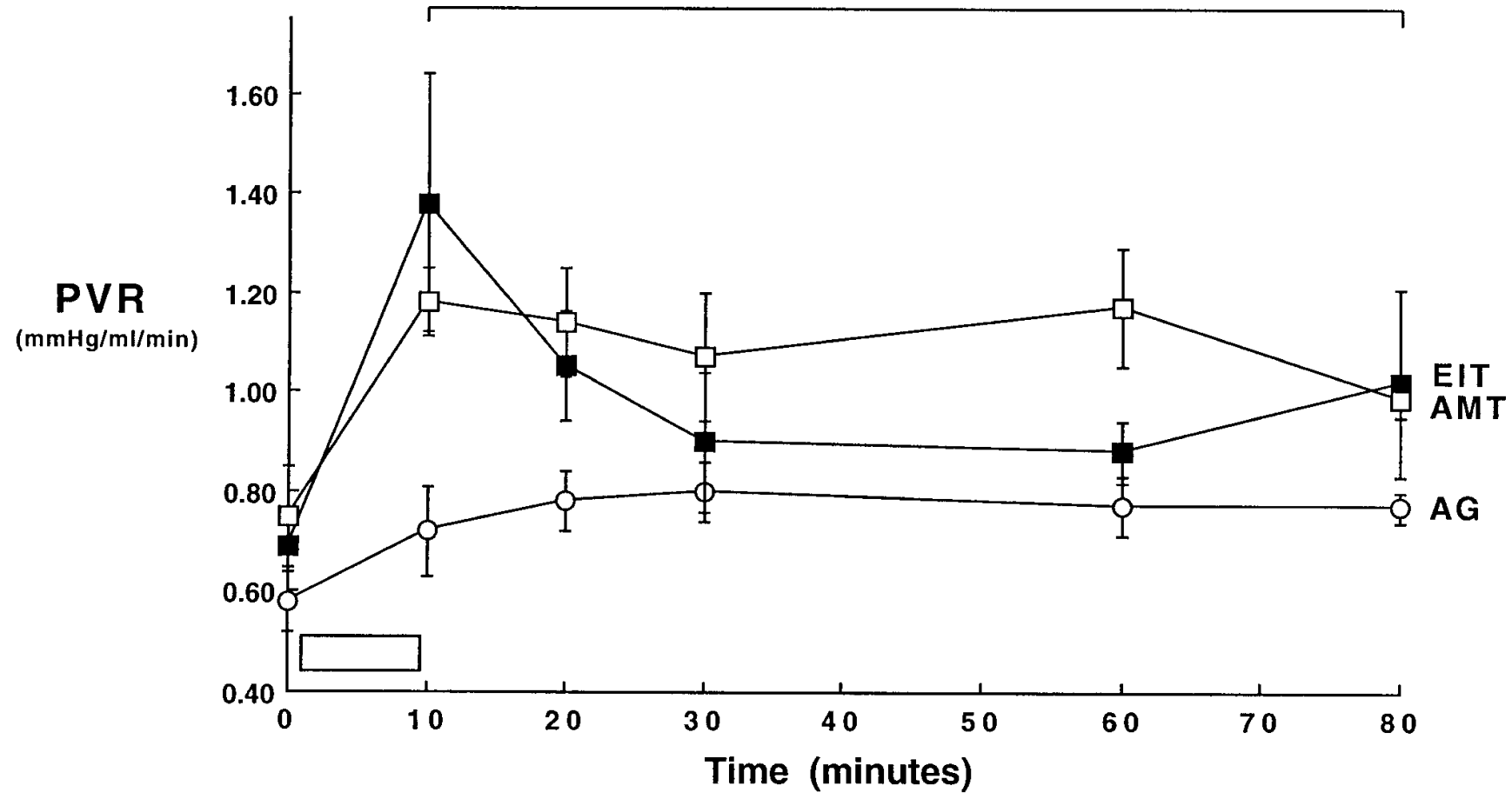

Figure 5. Prolonged effects of type II NOS inhibition on PVR in the late gestation fetus. PVR remained elevated for up to 80 min after treatment with each agent. Box represents infusion period for the antagonists.

nal, as it was detected with equal signal intensity to the larger transcript even after stringent washing conditions. The smaller size $2.6-\mathrm{kb}$ transcript may represent a reduction in the length of the $5^{\prime}$ or $3^{\prime}$ untranslated sequences, or it could result from alternative splicing of the primary transcript. The presence of more than one mRNA for type II NOS in lung tissue has been seen in other species, such as the rat $(8,32-34)$.

These findings are interesting because little is known about the role of type II NOS in the regulation of vascular tone in the normal fetal lung. Although type II NOS has been shown to play a role in the pathophysiology of shock, autoimmune disease, and chronic inflammation (18-21), few studies have expanded its potential physiologic roles in normal circulation. These data support the hypothesis that the inducible NOS isoform may play a constitutive role in the fetal pulmonary circulation (15).

Previous studies have demonstrated that maternal administration of a selective type II NOS inhibitor lead to constriction of the pulmonary artery, aorta, and ductus arteriosus in the fetal rat (15). However, it is uncertain if these hemodynamic ef-

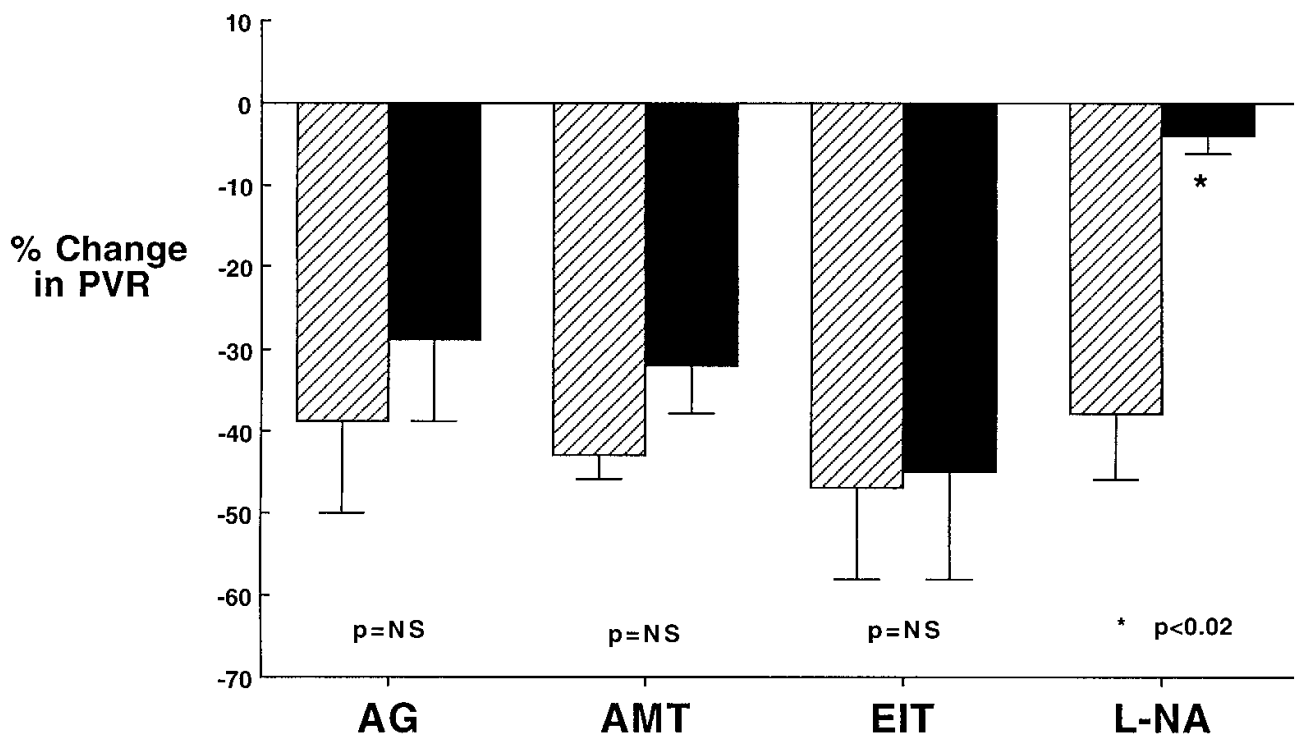

Figure 6. Effects of selective type II NOS antagonists (AG, AMT, and EIT) and a nonselective NOS antagonist (L-NA) on ACh-induced pulmonary vasodilation. Brief infusions of $\mathrm{ACh}$ decreased PVR by $35-45 \%$ from baseline. After the infusion of each study drug, ACh-induced pulmonary vasodilation was blocked after L-NA but not by the type II NOS blockers. Hatched bars, baseline ACh response; solid bars, treatment response. 


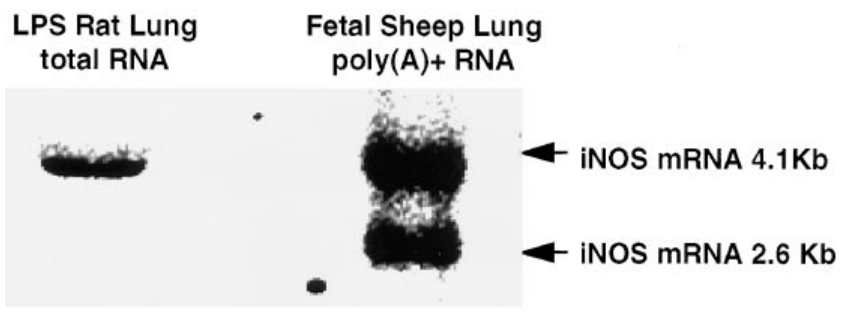

Figure 7. Northern blot analysis of type II NOS (iNOS) mRNA in the ovine fetal lung. $20 \mu \mathrm{g}$ of total RNA from the lungs of a rat injected with bacterial LPS to induce type II NOS expression and $20 \mu \mathrm{g}$ of poly (A) ${ }^{+}$RNA from a nonsurgical 136-d ovine fetal lung were subjected to Northern blot analysis using a mixture of mouse and human cDNA probes. Arrows indicate the size of the type II NOS mRNA transcripts detected.

fects were due to direct blockade in the fetal lung or secondary to effects on the maternal or placental circulation (for example, severe hypoxia or hypertension). To test the hypothesis that type II NOS activity regulates fetal hemodynamics, we infused type II NOS inhibitors directly into the left pulmonary artery of the chronically prepared late gestation fetus. Our findings that three different type II NOS inhibitors (AG, AMT, and EIT) increased pulmonary artery and aortic pressures, and decreased LPA blood flow, support the hypothesis that type II NOS is active in the fetus. These inhibitors did not increase the pressure gradient between the pulmonary artery and aorta, suggesting a lack of significant effect on the ductus arteriosus. However, it is possible that type II NOS inhibitors caused mild changes in ductus arteriosus tone, since changes in the pressure gradient are not extremely sensitive. Further studies specifically addressing the role of type II NOS on ductus arteriosus tone are needed. The increase in aortic pressure after infusion of the type II NOS antagonists further suggests a role for type II NOS in the systemic circulation.

Although each of the type II NOS inhibitors studied is competitive with L-arginine, their exact mechanisms of action are unclear. AG is thought to inhibit type II NOS by binding as a ligand to the heme iron at the catalytic site since AG deactivates other iron- or copper-containing enzymes in this manner (35). The isothioureas, AMT and EIT, have been demonstrated to alter the heme spectra of NOS, suggesting binding close to, or interaction with, the heme center $(28,35)$. L-NA's (an L-arginine analogue) mechanism of inhibition of NOS activity involves occupying the substrate binding site (35).

One of the potential limitations of pharmacologic studies of NOS antagonists includes the relative selectivity for the type II NOS isoform (35). Each agent has the potential at increased doses to also inhibit type I and III activity $(26,27)$. AG has been shown previously to have no effect on ACh-induced vasodilation, suggesting that AG inhibits type II NOS selectively without blocking constitutive NOS (22-25). AMT and EIT have been described recently as very potent and selective inhibitors of type II NOS (26-29). In vitro studies have shown that AG, AMT, and EIT are 80-, 40-, and 30-fold more potent for type II NOS than type III NOS, respectively $(26,27)$. The concentrations of drug needed to achieve $50 \%$ inhibition $\left(\mathrm{IC}_{50}\right)$ for AMT and EIT were 4 and $13 \mathrm{nM}$, respectively, indicating that these compounds are $\sim 1,000$-fold more potent than
AG $\left(\mathrm{IC}_{50}\right.$ value of $\left.12 \mu \mathrm{M}\right)(26,27)$. In our study, we showed that AG, AMT, and EIT elevated PVR without blocking ACh-induced pulmonary vasodilation, suggesting that these inhibitors inhibited type II NOS selectively without affecting constitutive type III (endothelial) NOS at the doses used in this study.

Dose responses to each of the selective type II NOS antagonists were not conducted in this study. The aim of this study was to determine if selective type II NOS antagonists would affect basal pulmonary vascular tone in the late gestation fetus. Initially, AG was infused at a dose of 1, 5, 10, and $40 \mathrm{mg}$ with no response (data not shown), and the ACh-induced vasodilation remained intact. A response was seen with AMT and EIT at a dose of $0.12 \mathrm{mg}$, and the ACh-induced pulmonary vasodilation remained intact. Therefore, based on previous studies in the literature with AMT and EIT being 1,000-fold more potent than $\mathrm{AG}(26,27)$, the dose of AG was increased to $140 \mathrm{mg}$, a response was seen, and the ACh-induced pulmonary vasodilation remained intact.

We conclude that selective type II (inducible) NOS antagonists increase PVR and systemic arterial pressure without decreasing oxygenation in the late gestation fetal lamb. These findings support the hypothesis that type II or inducible NOS contributes to the basal production of $\mathrm{NO}$ and modulation of basal vascular tone in the normal fetal circulation. Whether stimulation of type II NOS contributes to the release of NO and the marked decrease in PVR at birth is unknown.

\section{References}

1. Abman, S.H., B.A. Chatfield, S.L. Hall, and I.F. McMurtry. 1990. Role of endothelium-derived relaxing factor during transition of pulmonary circulation at birth. Am. J. Physiol. 259:H1921-H1927.

2. Cornfield, D.N., B.A. Chatfield, J.A. McQueston, IF. McMurtry, and S.H. Abman. 1992. Effects of birth-related stimuli on L-arginine-dependent pulmonary vasodilation in the ovine fetus. Am. J. Physiol. 262:H1363-H1368.

3. Davidson, D., and A. Eldemerdash. 1991. Endothelium-derived relaxing factor: evidence that it regulates pulmonary vascular resistance in the isolated newborn guinea pig lung. Pediatr. Res. 29:538-542.

4. McQueston, J.A., D.N. Cornfield, I.F. McMurtry, and S.H. Abman. 1993. Effects of oxygen and exogenous L-arginine on EDRF activity in the fetal pulmonary circulation. Am. J. Physiol. 264:H865-H871.

5. Shaul, P.W., M.A. Farrar, and T.M. Zellers. 1992. Oxygen modulates endothelium-derived relaxing factor production in fetal pulmonary arteries. Am. J. Physiol. 262:H355-H364.

6. Abman, S.H., B.A. Chatfield, D.M. Rodman, S.L. Hall, and I.F. McMurtry. 1991. Maturational changes in endothelium-derived relaxing factor activity of ovine pulmonary arteries in vitro. Am. J. Physiol. 260:L280-L285.

7. Fineman, J.R., J. Wong, F.C. Morin III, L.M. Wild, and S.J. Soifer. 1994 Chronic nitric oxide inhibition in utero produces persistent pulmonary hypertension in newborn lambs. J. Clin. Invest. 93:2675-2683.

8. Le Cras, T.D., C. Xue, A. Rengasamy, and R.A. Johns. 1996. Chronic hypoxia upregulates endothelial and inducible NO synthase gene and protein expression in rat lung. Am. J. Physiol. 260:L164-L170.

9. Tiktinsky, M.H., and F.C. Morin III. 1993. Increasing oxygen tension dilates fetal pulmonary circulation via endothelium-derived relaxing factor. Am. J. Physiol. 265:H376-H380.

10. Forstermann, U., and H. Kleinert. 1995. Nitric oxide synthase: expression and expressional control of the three isoforms. Naunyn-Schmiedeberg's Arch. Pharmacol. 352:351-364.

11. Halbower, A.C., R.M. Tuder, W.A. Franklin, J.S. Pollock, U. Forstermann, and S.H. Abman. 1994. Maturation-related changes in endothelial nitric oxide synthase immunolocalization in developing ovine lung. Am. J. Physiol. 267:L585-L591.

12. North, A.J., R.A. Star, T.S. Brannon, K. Ujiie, L.B. Wells, C.J. Lowenstein, S.H. Snyder, and P.W. Shaul. 1994. NO synthase type I and type III gene expression are developmentally regulated in rat lung. Am. J. Physiol. 266:L635L641.

13. Xue, C., P.R. Reynolds, and R.A. Johns. 1996. Developmental expression of NOS isoforms in fetal rat lung: implications for transitional circulation and pulmonary angiogenesis. Am. J. Physiol. 270:L88-L100.

14. Kobzik, L., D.S. Bredt, C.J. Lowenstein, J. Drazen, B. Gaston, D. Sug- 
arbaker, and J.S. Stamler. 1993. Nitric oxide synthase in human and rat lung: immunocytochemical and histochemical localization. Am. J. Respir. Cell Mol. Biol. 9:371-377.

15. Bustamante, S.A., Y. Pang, S. Romero, M. Pierce, C.A. Voelker, J.H. Thompson, M. Sandoval, X. Liu, and M.J.S. Miller. 1996. Inducible nitric oxide synthase and the regulation of central vessel caliber in the fetal rat. Circulation. 94:1948-1953.

16. Griffiths, M.J.D., S. Liu, N.P. Curzen, M. Messent, and T.W. Evans. 1995. In vivo treatment with endotoxin induces nitric oxide synthase in rat main pulmonary artery. Am. J. Physiol. 268:L509-L518.

17. Lui, S., I.M. Adcock, R.W. Old, P.J. Barnes, and T.W. Evans. 1993. Lipopolysaccharide treatment in vivo induces widespread tissue expression of inducible nitric oxide synthase mRNA. Biochem. Biophys. Res. Commun. 196: 1208-1213.

18. Kilbourn, R.G., A. Jubran, S.S. Gross, O.W. Griffith, R. Levi, J. Adams, and R.F. Lodato. 1990. Reversal of endotoxin-mediated shock by $N$-methylL-arginine, an inhibitor of nitric oxide synthesis. Biochem. Biophys. Res. Commun. 172:1132-1138.

19. Corbett, J.A., A. Mikhael, J. Shimizu, K. Frederick, T.P. Misko, M.L. McDaniel, O. Kanagawa, and E.R. Unanue. 1993. Nitric oxide production in islets from nonobese diabetic mice: aminoguanidine-sensitive and -resistant stages in the immunological diabetic process. Proc. Natl. Acad. Sci. USA. 90: 8992-8995.

20. Farrell, A.J., D.R. Blake, R.M.J. Palmer, and S. Moncada. 1992. Increased concentrations of nitrite in synovial fluid and serum samples suggest increased nitric oxide synthesis in rheumatic diseases. Ann. Rheum. Dis. 51:12191222.

21. Jansen, A., T. Cook, G.M. Taylor, P. Largen, V. Riveros-Moreno, S. Moncada, and V. Cattell. 1994. Induction of nitric oxide synthase in rat immune complex glomerulonephritis. Kidney Int. 45:1215-1219.

22. Corbett, J.A., R.G. Tilton, K. Chang, K.S. Hasan, Y. Ido, J.L. Wang, M.A. Sweetland, J.R. Lancaster, Jr., J.R. Williamson, and M.L. McDaniel. 1992. Aminoguanidine, a novel inhibitor of nitric oxide formation, prevents diabetic vascular dysfunction. Diabetes. 41:552-556.

23. Griffiths, M.J.D., M. Messent, R.J. MacAllister, and T.W. Evans. 1993. Aminoguanidine selectively inhibits inducible nitric oxide synthase. Br. J. Pharmacol. 110:963-968.

24. Joly, G.A., M. Ayres, F. Chelly, and R.G. Kilbourn. 1994. Effects of
$N$-methyl-L-arginine, $N$-nitro-L-arginine, and aminoguanidine on constitutive and inducible nitric oxide synthase in rat aorta. Biochem. Biophys. Res. Commun. 199:147-154.

25. Yen, M., S. Chen, and C. Wu. 1995. Comparison of responses to aminoguanidine and $N$-nitro-L-arginine methyl ester in the rat aorta. Clin. Exp. Pharmacol. Physiol. 22:641-645.

26. Nakane, M., V. Klinghofer, J.E. Kuk, J.L. Donnelly, G.P. Budzik, J.S. Pollock, F. Basha, and G.W. Carter. 1995. Novel potent and selective inhibitors of inducible nitric oxide synthase. Mol. Pharamacol. 47:831-834.

27. Tracey, W.R., M. Nakane, F. Basha, and G. Carter. 1995. In vivo pharmacological evaluation of two novel type II (inducible) nitric oxide synthase inhibitors. Can. J. Physiol. Pharmacol. 73:655-669.

28. Garvey, E.P., J.A. Oplinger, G.J. Tanoury, P.A. Sherman, M. Flower, S. Marshall, M.F. Harmon, J.E. Paith, and E.S. Furfine. 1994. Potent and selective inhibition of human nitric oxide synthases. J. Biol. Chem. 269:26669-26676.

29. Calaycay, J.R., T.M. Kelly, K.L. MacNaul, E.D. McCauley, H. Qi, S.K. Grant, P.R. Griffin, T. Klatt, S.M. Raju, A.K. Nussler, et al. 1996. Expression and immunoaffinity purification of human inducible nitric-oxide synthase. $J$. Biol. Chem. 247:28212-28219.

30. Ivy, D.D., T.A. Parker, J.W. Ziegler, H.L. Galan, J.P. Kinsella, R.M. Tuder, and S.H. Abman. 1997. Prolonged endothelin A receptor blockade attenuates chronic pulmonary hypertension in the ovine fetus. J. Clin. Invest. 99: 1179-1186.

31. Lewis, A.B., M.A. Heymann, and A.M. Rudolph. 1976. Gestational changes in pulmonary vascular responses in fetal lambs in utero. Circ. Res. 39 $536-541$.

32. Villamor, E., T.D. Le Cras, M.P. Horan, A.C. Halbower, R.M. Tuder, and S.H. Abman. 1997. Chronic intrauterine pulmonary hypertension impairs endothelial nitric oxide synthase in the ovine fetus. Am. J. Physiol. 272:L1013L1020.

33. Chomczynski, P.A. 1994. A reagent for the single-step simultaneous isolation of RNA, DNA and proteins from cell and tissue samples. Biotechniques. 15:532-534.

34. Sambrook, J., E.F. Fritsch, and T. Maniatis. 1989. Molecular Cloning: A Laboratory Manual. 2nd ed. Cold Spring Harbor Laboratory Press, Cold Spring Harbor, NY. 187-208.

35. Southan, G.J., and C. Szabo. 1996. Selective pharmacological inhibition of distinct nitric oxide synthase isoforms. Biochem. Pharmacol. 51:383-394. 